\title{
EDUCAÇÃO E HUMANIZAÇÃO NA PERSPECTIVA DA JUSTIÇA SOCIAL EM FREIRE: DIÁLOGOS CONVERGENTES E AMPLIADOS
}

\author{
EDUCATION AND HUMANIZATION IN FREIRE'S SOCIAL JUSTICE PERSPEC- \\ TIVE: converging and expanded dialogues
} EDUCACIÓN Y HUMANIZACIÓN EN LA PERSPECTIVA DE LA JUSTICIA SO-
CIAL EN FREIRE: diálogos convergentes y expandidos

\author{
Marina Graziela Feldmann \\ Professora Doutora da Pontifícia Universidade Católica (PUC-SP). \\ feldmnn@uol.com.br \\ Maria de Nazaré Corrêa Silva \\ Doutoranda em Educação: Currículo pela Pontifícia Universidade Católica (PUC-SP) \\ professoranazareuea@hotmail.com \\ Marcos Tarciso Masetto \\ Professor Doutor da Pontifícia Universidade Católica (PUC-SP). \\ mmasetto@gmail.com
}

\begin{abstract}
RESUMO: O artigo analisa uma experiência realizada por meio de um projeto de extensão do Curso de Pedagogia da Universidade do Estado do Amazonas (UEA), através do Programa de Letramento Reescrevendo o Futuro (PLRF). Tal projeto elegeu a temática Educação e Humanização, com ênfase no iletrismo existente junto às populações de baixa renda e excluídas socialmente. Para tanto, foram analisados documentos com o registro das ações desenvolvidas. Os resultados evidenciaram: baixa evasão, diminuição em $50 \%$ dos indicadores negativos, letramento com as temáticas trazidas pelos estudantes, possibilidade de leitura do mundo a partir da realidade do grupo, inserção no ensino formal, retorno aos lares, aumento da autoestima e autorreconhecimento de seu inacabamento, mesmo na condição de se sentirem de e na rua.
\end{abstract}

PALAVRAS-CHAVE: Educação. Humanização. Moradores de rua. Prática docente.

ABSTRACT: The article analyzes an experiment carried out through an extension project by the Department of Pedagogy at Amazonas State University (UEA), through the Literacy Program Rewriting the Future. This project has chosen the Education and Humanization theme, with emphasis on existing illiteracy in low-income population and socially excluded people. Therefore, documents were analyzed considering what was registered about the actions. The results showed: low dropout rate, decreased negative indicators by $50 \%$, literacy withthemes brought by the students, possibility of reading the world from the group's reality, inclusion in formal education, return to their homes, increased self-esteem and self-recognition of their incompleteness even when they feel from and on the street.

KEYWORDS: Education. Humanization. Homeless. Teaching practice.

RESUMEN: El artículo analiza un experimento llevado a cabo por medio de un proyecto de extensión del Curso de Pedagogía de la Universidad del Estado de Amazonas (UEA), a través del Programa de Letramiento Reescribiendo el Futuro (PLRF). Este proyecto eligió el tema de Educación y Humanización, con énfasis en el analfabetismo existente con las poblaciones pobres y excluidas socialmente. Así, fueron analizados documentos con el registro de las acciones desarrolladas. Los resultados mostraron: baja evasión, disminución en un $50 \%$ de los indicadores negativos, letramiento con los temas presentados por los estudiantes, posibilidad de leer el mundo a partir de la realidad del grupo, inclusión en la educación formal, retorno a los hogares, aumento de la autoestima y autoconocimiento de su carácter incompleto, incluso en condiciones de sentirse en situación de y en la calle.

PALABRAS CLAVE: Educación. Humanización. Personas en situación de calle. Práctica docente.

Artigo recebido em setembro de 2016

Aprovado em novembro de 2016 


\section{1| INTRODUZINDO A QUESTÃO}

Nos estudos e encontros do Grupo de Pesquisa Formação de Professores e Cotidiano Escolar, certificado pelo Conselho Nacional de Desenvolvimento Científico e Tecnológico (CNPq), do Programa de Pós-Graduação em Educação: Currículo da Pontifícia Universidade Católica de São Paulo, buscamos a ampliação do entendimento do que significa uma educação contextualizada, relacional e humanizada, ancorada no pensamento de Paulo Freire. Esse grupo é constituído por docentes e pesquisadores da graduação e pós-graduação, por alunos de mestrado e doutorado que realizam estudos e pesquisas que privilegiam a articulação possível e necessária entre os saberes da experiência e os fundamentos teóricos relacionados, o que se consubstancia em entender a ação educativa sempre como um trabalho revestido da perspectiva da incompletude, complexidade e multirreferencialidade. É sempre uma forma fractal de interrogar o mundo que nos envolve e nos define. Entender dessa forma a educação exige, como explica Feldmann (2009),

tomá-la em sua concretude, em sua manifestação histórica, política e social [...]. Envolve relações entre as pessoas, projetos e processos que se produzem mutuamente contraditoriamente embasados em uma visão de homem, mundo, natureza e sociedade (FELDMANN, 2009, p. 72).

As pessoas se tornam educadores quando se educam com o outro, ao produzirem sua existência relacionada com a existência do outro, um processo permanente de apropriação, mediação e transformação do conhecimento mediante um projeto existencial ético e coletivo de construção humana.

Pensar a formação permanente de educadores com base fulcral no pensamento freireano tem exigido do grupo a busca de convergências em diferentes pesquisas, de forma a problematizar os processos formativos, as relações pedagógico-educativas, a dimensão dialética do ensinar e do aprender dentro do cenário político e social que envolve tais questões. Pensar a formação de educadores é sempre pensar a formação do humano, e, nessa perspectiva, se vislumbra a construção de ações transformadoras, em qualquer que seja o seu contexto de ação. Tais ações promovem uma mudança concebida por nós como

aprimoramento da condição humana, liberdade de expressão e comunicação e desenho de possibilidades de um mundo melhor, de uma melhor convivência entre as pessoas. Convivência essa permeada pelos valores da solidariedade, do respeito ao outro, às diferenças de crenças, etnias, gênero, religiões [...]. Mas sabemos também que uma melhor convivência entre as pessoas- ou seja, viver melhor com o outro- não se encerra apenas com intenções, com palavras destituídas de significados, mas se concretiza quando por meio de projetos coletivos se estiver visceralmente atrelado à luta permanente contra as estruturas desumanizantes presentes em nossa educação e em nossa sociedade (FELDMANN, 2009, p.76).

Trabalhamos com a concepção de contexto, aprendizado e humanização caracterizando-os como temas fundantes de currículo, que pode ser entendido como a construção epistemológica e social do conhecimento, concretizada em espaços educativos e vivenciada nos valores, projetos e discursos, dando sentido à vida e ao trabalho das pessoas. Parafraseando o nosso saudoso ex-professor Paulo Freire, que sempre nos dizia em nossas aulas e encontros: não há conhecimento se ele não for molhado pela realidade concreta que nos envolve.

O aprender algo em nossas vidas está sempre atrelado ao desenho de um contorno - o contexto em que vivemos e convivemos, o qual vai além do entendimento de um espaço físico, de um 
ambiente, mas se constitui também e principalmente pelo processo de comunicação, que por meio do imaginário das pessoas cria discursos revelando pensamentos e concepções na busca do sentido ético da conduta humana.

Nos ensinamentos de Paulo Freire a vocação ontológica do ser humano é a humanização. $E$ devido à sua incompletude ele é situado em permanente busca de humanização. A dialeticidade humanização-desumanização no cotidiano se configura na possibilidade de homens e mulheres, como seres inconclusos e mergulhados na vida real, sonharem e lutarem por um mundo mais humano, solidário, democrático com a esperança de transformar-se e transformar o outro.

O nosso Grupo de Pesquisa tem se concentrado em estudos e pesquisas sobre o entrelaçamento da tríade conhecimento, contexto e humanização, tomando-a como constitutiva dos sujeitos curriculares - educadores, uma vez que a identidade pessoal e profissional é também construída por meio dos significados e símbolos existentes nos espaços educativos vivenciados.

O pensamento freireano tem iluminado os nossos estudos, constituindo conjuntamente com outros autores o referencial teórico e prático, no qual se alicerçam as pesquisas dos participantes do grupo. Assim, apresentamos as reflexões provenientes de uma pesquisa realizada por meio de um projeto de extensão do Curso de Pedagogia da Universidade do Estado do Amazonas (UEA), através do Programa de Letramento Reescrevendo o Futuro (PLRF), o qual resolveu, entre 2009-2010, eleger uma problemática para atuar junto às populações de baixa renda no estado do Amazonas, apresentada a seguir.

\section{2 | A INFLUÊNCIA FREIREANA NO PROJETO DE EXTENSÃO DE CURSO DE PEDAGOGIA DA UNIVERSIDADE DO ESTADO DO AMAZONAS (UEA)}

Paulo Freire criou um caminhar filosófico epistêmico próprio, com a cara e a voz do "oprimido", com grandes possibilidades de transformação do espaço vivido e sentido na concreticidade do cotidiano e de "andarilhagem" de muitos "uns". Esta "andarilhagem", aqui posta de forma especial, tem a identidade da Amazônia, retratada no regionalismo da obra "Aquele Um" de Benedicto Monteiro nos anos 80 e nas andanças dos moradores de rua que vagam dia e noite nos espaços urbanos de Manaus, capital do Amazonas, de onde fala uma das pesquisadoras. Parece até que Kosik (1976) também bebeu nesta literatura quando pensou no mundo da pseudoconcreticidade. Percebemos esta aproximação quando Loureiro (apud ROSA, 2003, p.31) destaca: "Para o caboclo, plantador e pescador de símbolos, a imagem parece estar constituída de uma força própria, criadora de uma realidade instaurada de novos mundos, capaz de ultrapassar o simples campo de escombros da memória". Prossegue dizendo:

\footnotetext{
Homem e natureza são integrantes de um mesmo cosmo representado no romance pelo personagem Miguel dos Santos Prazeres. Sem profissão definida - balateiro, mateiro, pescador, vaqueiro, caçador, juteiro, pirotécnico - Miguel é o homem típico da Amazônia, que segue em sua canoa gita por entre furos e ilhas, nos fluxos e refluxos das marés, buscando para o seu mundo uma explicação, que só vem de forma alegórica através do imaginário social (LOUREIRO apud ROSA, 2003, p. 31).
}

Como expõe Freire nas obras Pedagogia da Autonomia (1996), Pedagogia do Oprimido (1987), e Conscientização (2008), o mundo precisa ser mais humanizado e, um dos caminhos, é a educação com leitura crítica do mundo para além de uma aprendizagem técnica de codificação e decodificação. 
Na sala de aula, os participantes são desafiados a ajustar suas lentes para a leitura da realidade e para a teoria em estudo. Esse exercício se materializa nas várias situações-problema em que cada participante traz para a roda de conversa na busca de ser mais: situações da vida rotineira, da gestão escolar, das coordenações pedagógicas, das pesquisas em desenvolvimento, da observação feita nos estabelecimentos onde é desenvolvida sua prática educativa ou proveniente dos estudos a respeito de alguém que lhe é caro. Também, e, com muita ênfase, refletimos acerca do momento político que vive o país. Esse momento exige uma inflexão no pensamento de Freire e, portanto, um posicionamento de valores com distintos diálogos. Falas como: Olha, a escola não pode ser isolada! Não vou fazer isso ou aquilo, pois me sentiria traindo o pensamento de Freire. São princípios e proposições de como vemos a filosofia de uma educação na perspectiva da humanização e das relações sociais se materializando.

Na perspectiva da humanização, um dos anseios registrados ao longo de diversas discussões ocorridas no projeto desenvolvido pelo curso de Pedagogia da UEA trata da questão de gênero. Afirma Gadotti (1991) que A Declaração de Nova Delhi e o Marco de Ação de Dakar acentuaram as desigualdade quanto a condição de gênero em seus documentos, considerando que, de 100 milhões de crianças, $60 \%$ são meninas sem o ensino primário e dos 960 milhões de adultos, $2 / 3$ são mulheres analfabetas. Apesar dos dados referirem-se ao contexto da Índia, a educação brasileira também possui uma enorme dívida social com sua população não somente quanto ao gênero. Jovens e adultos de diferentes grupos étnicos continuam sofrendo as mais injustas privações educacionais. Configura-se, nesse contexto a existência do ser menos (FREIRE, 1997). Como reverter essa situação? Com propriedade, acerca de injustiça, Torres Santomé (2013) alude que:

\begin{abstract}
Uma vez que não é admissível atribuir os sucessos e fracassos escolares a problemas na estrutura dos genes, aos dons outorgados por alguma divindade, à situação dos astros no firmamento no momento no momento do seu nascimento ou a qualquer outra explicação, irracional, [...] um dos desafios mais importantes dos atuais sistemas educativos é contribuir para a aprovação escolar e assegurá-la (grifo nosso). A reprovação escolar, ao menos nas etapas obrigatórias do sistema, sempre é uma manifestação de denúncia da existência de uma sociedade injusta. A luta por justiça exige um comprometimento inescusável com os alunos procedentes de situações e grupos sociais desfavorecidos social, cultural e economicamente. Ela obriga a garantia de uma educação apropriada a cada estudante em particular, independentemente de suas capacidades intelectuais, seus tipos de inteligência seus estilos de aprendizagem, suas capacidades físicas e sensoriais, suas crenças religiosas e culturais, sua etnia, sua sexualidade, seu gênero e sua classe social (TORRES SANTOMÉ, 2013, p. 224).
\end{abstract}

Na docência temos um leque robusto que nos desafia ao enfrentamento e à tomada de consciência. O/A professor/a não se basta pelo domínio do conteúdo, mas, tão somente e verdadeiramente, por sua prática social. Esta prática se constitui num importante instrumento de organização contra-hegemônica para o enfrentamento à violação dos direitos humanos, como: "os direitos civis e políticos; os direitos sociais, também chamados de coletivos; e os direitos culturais e ambientais; também em curso o direito de solidariedade humana" (CALDART, et al, 2012, p. 224). A prática social do/a professor/a deve refletir sua posição perante os atos desumanos que produzem males como a fome, a doença a insegurança, a deseducação, dentre outros, que afetam milhões de pessoas e que continuam sendo considerados fatalidades ou, pior, são atribuídos à responsabilidade das próprias pessoas que delas padecem.

O pensamento de Freire recusa com rigor os fatalismos quietistas que absorvem as transgressões de uma ordem perversa culpando-o por sua malvadez, ao atribuir a 'forças cegas' e imponderáveis os danos por elas causados a mulheres e homens. A educação na humanização e 
na busca do ser mais nos remete ao entendimento freireano de que o ser humano é por sua "natureza" inacabado, mas que tem consciência de sua inconclusão. Todavia, só entre homens e mulheres 'oprimidos', com seus direitos humanos afetados, o inacabamento se tornou consciente através do conhecimento para a transformação da realidade indesejada. Para tal, cabem as questões "quem é o homem, o que é a sociedade humano-social e como é criada esta sociedade?" (KOSIK, 1976, p. 200). A mesma inquietação está em Freire quando reflete sobre educação:

O que é o homem, qual a sua posição no mundo? - são perguntas que temos que fazer no momento mesmo em que nos preocupamos com educação. Se essa preocupação, em si, implica nas referidas indagações..., a resposta que à ela dermos encaminhará a educação para uma finalidade humanista ou não (FREIRE, 1997, p. 9).

Para Kosik (1976),

o complexo dos fenômenos que povoam o ambiente cotidiano e a atmosfera da vida humana, [constitui o que ele denominou de] mundo da pseudoconcreticidade [do qual fazem parte], o mundo dos fenômenos externos [...], o mundo do tráfico e da manipulação [...], o mundo das representações [...] e o mundo dos objetos fixados [...] (KOSIK 1976, p. 11).

Neste quarto mundo, os objetos dão a impressão de serem condições naturais e, portanto, não são imediatamente reconhecíveis como resultado da atividade social dos homens.

Eis aí o papel do educador na produção do conhecimento para além dessa ótica. Se sua prática for comprometida com a transformação desse status quo, perseguirá a destruição ou desconstrução deste olhar petrificado na consciência do sujeito resultando num quefazer cada vez mais humanizado e libertador. Do contrário, nossa ação educativa se processaria em termos mecanicistas, de naturalização das "coisas", contribuindo cada vez mais, para uma ação domesticadora (FREIRE, 1997, p. 9).

Em Dialética do Concreto, Kosik (1976) afirma que a dialética não considera os produtos fixados, suas configurações, os objetos, e todo o conjunto do mundo material reificado como algo originário e independente. $\mathrm{O}$ autor submete o mundo dos objetos fixados, a exemplo dos demais mundos, a um exame em que as formas reificadas do mundo objeto e ideal se diluem, perdem a sua fixidez, naturalidade e pretensa originalidade para se mostrarem como fenômenos derivados e mediatos, como sedimentos e produtos da práxis social da humanidade. É possível observar uma aproximação estreita do saber filosófico de Kosik (1976) com o de Freire (1997), quando o segundo diz,

Não posso, igualmente, coisificar meus alunos, coisificar o povo, manipulá-los em nome de nada. Por vezes, ou quase sempre, para justificar tais atos indiscutivelmente desrespeitosos das pessoas, busca-se disfarçar seus objetivos verdadeiros com explicações messiânicas [...] todavia, um ponto que não se deve esquecer. Ninguém pode buscar sozinho. Toda busca no isolamento, toda busca movida por interesses pessoais e de grupos, é necessariamente uma busca contra os demais. Consequentemente, uma falsa busca (FREIRE, 1997, p. 11). 
EDUCAÇÃO E HUMANIZAÇÃO | Marina Feldmann, Marcos Masetto e Maria de Nazaré Silva

\section{3 | EDUCAÇÃO E HUMANIZAÇÃO NO ESTADO DO AMAZONAS}

A exemplo de outras capitais e centros urbanos das grandes cidades, como expressam os pensamentos de Peres (2002) e Souza (2007), Manaus, capital do Estado do Amazonas, se modificou e passou a ser considerada a "Paris dos Trópicos" até os anos de 1940 e 1950. É necessário retornar à década de 1940 para compreender melhor os contornos físicos e sociais do contexto municipal. Nos anos de 1940, Manaus era considerada por cronistas da época uma modesta cidade de pouco mais de 100 mil habitantes, quando era possível conviver com seus contrates arquitetônicos de origem inglesa, em meio à floresta fechada e entrecortada de rios e igarapés. Nessa época, Manaus viu nascer teatros, mercado, bonde, cabarés, igrejas e um forte comércio. Na floresta, rios e igarapés, mantinha-se escondido, em taperas e flutuantes, o que não deveria ser visto por "turistas" nem tampouco misturado com a classe dominante local composta pelos coronéis da borracha, intelectuais dirigentes e frequentadores da Universidade Livre de Manaus, desde a sua criação em 1909.

Porém, a partir dos anos de 1960, passou a ser mais um local com aglomeração populacional descontrolada, fruto dos interesses do capital industrial e cosmopolita que ocorre a partir da implantação da Zona Franca. Juntamente com o propalado desenvolvimento, foram atraídos povos de diferentes cidades, intensificando o êxodo rural, sendo visível o esvaziamento e abandono dos seringais que sustentaram o primeiro ciclo econômico da Amazônia. Além disso, pessoas de outros países também se instalaram na cidade.

Hoje, com aproximadamente 2,5 milhões de habitantes, suas contradições se multiplicaram e se tornaram visíveis às lentes dos cientistas sociais e da população que visita ou transita pelo centro da cidade. Seus moradores de rua se instalam preferencialmente nas imediações do Teatro Amazonas, Largo de São Sebastião, Centro de Artes da Universidade Federal do Amazonas, Mercado Municipal Adolpho Lisboa, Igreja da Matriz Nossa Senhora da Conceição e feiras. Esses locais lhes oferecem abrigo, migalhas de alimentos, possibilidades de esmolas e pequenos serviços de limpeza e "expiação" de automóveis realizados como "bicos". Vale ressaltar que subjazem à situação dos moradores de rua os problemas como a falta de humanização e educação existentes nas grandes cidades. Com propriedade, Freire (1991) defende que a prática docente para a liberdade e autonomia dos sujeitos deve estar consubstanciada de paixão ou amorosidade, como gostava de definir, ou seja, uma prática que venha na contramão da perspectiva neoliberal que expressa no ensino técnico e livresco, conduz o educando às incessantes adaptações.

O Curso de Pedagogia da Universidade do Estado do Amazonas (UEA), como em outras áreas de extensão universitária, através do Programa de Letramento Reescrevendo o Futuro (PLRF), resolveu entre 2009-2010 eleger uma problemática para atuar junto às populações de baixa renda no estado do Amazonas. A temática eleita foi "Educação e Humanização", com ênfase no iletrismo, no baixo grau de alfabetismo desse público de jovens e adultos e em sua exclusão social. Os problemas foram identificados, observando-se o desumano tratamento dado ao iletrismo nos municípios do estado do Amazonas que à época, variava de 6\% em Manaus a 60\% em Itamarati, segundo dados do Censo de 2000 verificados pela universidade em questão. O público selecionado abrangeu ribeirinhos, pescadores, agricultores, indígenas de 36 etnias, povos da floresta, iletrados em vulnerabilidade social, privados de liberdade, afrodescendentes, donas de casa, trabalhadores urbanos e rurais e moradores de rua da cidade de Manaus, objeto desta pesquisa. E foi justamente pensando em garantir a essas pessoas um direito que lhes foi negado em função dos fatores socioeconômicos, espaciais, ambientais, geracionais, étnicos e de gênero, que, segundo a coordenação do projeto em estudo, a universidade estadual planejou esta ação. 
Os procedimentos da investigação estão ancorados em um estudo teórico e documental tomando como referencial principal Freire (1987, 1991, 1996, 1997), Karel Kosik (1976), Michel Lowy (1978) e Garcez et al (2011). Os objetivos da pesquisa se constituem em: 1) identificar nas práticas docentes articuladas a políticas de letramento os princípios freireanos compreendidos na relação entre educação e humanização. 2) Analisar uma prática educativa tendo como foco a humanização para promover o retorno dos educandos excluídos ao contexto social considerado digno. Os documentos acessados foram relatórios da Universidade do Estado do Amazonas e vídeos com registros da ação desenvolvida no centro da cidade de Manaus, nos espaços do complexo religioso da Igreja de São Sebastião situada no Largo de mesmo nome.

O grupo que compôs o projeto analisado por meio de vídeo se constituiu de aproximadamente vinte e cinco educandos, duas educadoras/alfabetizadoras e equipe pedagógica da UEA. O documento gravado inicia retratando o locus de moradia dos sujeitos aprendizes e sua acolhida, para Ihes ser apresentada a possibilidade de retorno aos estudos e, por certo, de ressocialização. Foram disponibilizados os seguintes serviços: higienização com uso de sabonete líquido, corte de cabelo e feitura de barba aos que aderiram, entrega de roupas limpas e higienizadas. Todo o material foi colhido de doações no comércio local e dos moradores nos arredores do Largo, como poder ser observado no vídeo e nos relatórios. A pesquisa assumiu a postura recomendada, como a indicada por Garcez et al (2011), que prevê, na pesquisa qualitativa com vídeo gravação, uma sequência sistemática para que o objeto em análise seja percebido nos detalhes de distintas linguagens. Assim, para eles, o modelo apresentado pode ajudar os pesquisadores a compreenderem de forma mais apurada seus dados e economizar tempo nas análises. Defendem que os vídeos deixam o objeto mais perceptível ao ponto de tornar, tanto o vídeo quanto as transcrições, dados da pesquisa.

Para Freire (1987, 1996), o mundo precisa ser mais humanizado, e um dos caminhos é a educação com leitura crítica do mundo para além de uma aprendizagem técnica de codificação e decodificação. Esta foi a tônica da ação, fundamentada em princípios freireanos. Não foi fácil. À época, talvez, havia mais vontade e sonhos de empoderar para transformação social do que a preocupação no domínio das categorias que solidificaram esta teoria. No entanto, havia a compreensão de que a equipe precisava ser radical no compromisso com as lutas por humanização e resistir contra as atrocidades em relação à vida concreta das pessoas.

Entre os objetivos do projeto, encontramos:

Integrar a política de combate ao iletrismo do governo federal e estadual, com abordagens ambientais, sociais nutricionais e de gênero, no campo das preocupações do meio ambiente e do desenvolvimento humano sustentável, na perspectiva do enfrentamento à causa e empoderamento dos sujeitos (UNIVERSIDADE DO ESTADO DO AMAZONAS, 2009).

Amparada no princípio das abordagens sociais, nutricionais e do desenvolvimento humano na perspectiva do enfrentamento do problema, a coordenação do projeto articulou iniciativas com outras instituições que viessem atender a esses propósitos. As principais instituições parceiras desta prática foram: Ministério da Educação/Brasil Alfabetizado/FNDE, Governo do Estado do Amazonas, prefeituras municipais acolhedoras e vigilantes desta ação, SEDUC/Secretaria de Estado da Educação, SEAS/Secretaria de Assistência, Congregação de Padres Franciscanos/ Capuchinhos do Projeto "Parceria pela Vida", responsáveis pela capacidade instalada e controle do material disponibilizado para as aulas.

Ao ser entrevistada sobre a viabilidade da ação com esse público, a coordenadora pedagógica da universidade reflete: 


\begin{abstract}
Eles/as precisam primeiro acreditar nessa possibilidade de voltarem a estudar, de que este espaço é deles, que é um direito deles ocuparem e que, com certeza, eles/as terão uma oportunidade maior voltando ao ensino oficial. O PLRF não tinha a pretensão de ser tão abrangente da forma e com as especificidades e as diferenças populacionais que nós temos. Mas, à medida que o tempo passa, a credibilidade ao programa aumenta e as parcerias não vêm uma após a outra, elas acontecem concomitantemente. Elas só estão, por assim dizer, dialogando, atingindo um público cada vez mais resistente ao processo de educação, o que sem dúvida se constitui num extremo desafio para a equipe do programa (COORDENADORA PEDAGÓGICA, 2009).
\end{abstract}

Avaliamos que as intenções expressas pela responsável pedagógica em nível da instituição foram de crença na possibilidade de intervir junto a esses sujeitos, com pressupostos teóricos humanizadores que se aproximam de uma visão, exposta por Lowy (1985), ao tratar do humanismo enquanto essência humana eterna, desvelando diferença e igualdade quando diz que os principais momentos do humanismo do materialismo dialético são:

1) O desvendamento das relações entre os homens atrás das categorias reificadas da economia capitalista;

2) A crítica da desumanidade do capitalismo;

3) O socialismo como possibilidade objetiva de uma sociedade onde a produção é racionalmente controlada pelos homens. (LOWY, 1985, p. 63)

Em suas entrelinhas, Freire (1997) comunga com tais princípios quando alude que somente o homem é capaz de admirar e objetivar o mundo, enquanto ser incompleto e vivendo em um tempo que é seu e tem nesse mundo um não eu constituinte do seu eu. Isso implica, para ele, em não apenas estar no mundo, mas com ele e nele atuar. Ele chamou a isso de concepção humanista e libertadora. Essa compreensão, passa pelo projeto de sociedade que ficou visível no relato acima, ou seja, foi possível captar a realidade, intervir e transformá-la.

As estratégias didático-metodológicas consistiram em aulas aos sábados, dois professores por turma, escolha dos temas geradores no círculo de diálogos, não utilização de cartilhas, saraus literários, três refeições diárias, transporte, amorosidade coletiva a partir da escuta a esse ser incompleto e ávido de carinho e amorosidade. Além disso, houve a oferta de ações via merendas pedagógicas e uma bolsa de incentivo a assiduidade no valor de trinta reais a cada mês frequentado. Desta forma, a ação buscou suprir as necessidades básicas imediatas para garantir o ingresso e permanência dos/as moradores/as de rua no projeto.

Paulo Freire aduz que se o homem é esse ser inacabado, da busca permanente, em função de ter consciência disso, essa busca implica na existência de um sujeito da ação, neste caso os/ as moradores/as de rua, e o objeto básico da busca foi a humanização enquanto imperativo a ser existencializado.

O mundo circundante descrito por essa população, sobrevivente das ruas de Manaus, é cheio de temor e opressão, como ouvimos nas falas iniciais de Cleu, Vag e Van:

Por mais que a casa tivesse cheia de gente, toda vez eu me sentia só (CLEU, MR/Mao, 2009); Eu fico ali na Caixa Econômica, sendo agredido, agredido por cheiras-cola. O problema que eu tinha era a bebida, hoje não bebo mais, eu era alcóolatra, eu bebia cachaça direto (VAG, MR/Mao, 2009); Eu saio de casa, passo quase um mês fora dela. Assim, mais também por causa de brigas, aí eu volto pra casa porque sinto falta de casa e fico querendo voltar. Às vezes, vou em casa ver a menina, a outra tem dezoito anos e o menino tem 20 (VAN, MR/Mao, 2009). 
Vag, Cleu e Van eram moradores de rua em Manaus no ano de 2009. Eles vagavam pelo centro da cidade. Nas ruas, mantiveram contato constante com a exclusão, o vício, a pobreza e a violência. Não mantinham contato diário com a família e já tiveram passagens pela polícia. Mas a pesquisa constatou que até mesmo nas ruas houve esperança de recomeçar. Percebemos que na ação desenvolvida pela universidade, em parceria com outras instituições e, com a oferta de estrutura compatível com as necessidades deles/as, como espaço físico próximo aos locais por eles/as frequentados/as, foi possível entender o que Paulo Freire nos remete sobre os termos amorosidade e humanização, aspectos tratados neste trabalho. O projeto para esses sujeitos se constituiu em um dos caminhos viáveis à conquista da cidadania. Seria essa oportunidade um "inédito viável" da forma como é abordado por Freire?

A dupla de professoras selecionadas e que, de forma voluntária, aderiu à proposta, era composta por estudantes do Curso de Pedagogia das universidades federal e estadual do Amazonas. Em conversa uma delas relata no vídeo:

Trabalhar com esse público para mim foi muito bom. Porque, logo que a Universidade do Estado do Amazonas nos apresentou a demanda e nos liberou para trabalhar com esse público aqui, nós ficamos assim... Confesso que fiquei apreensiva porque era um público de moradores de rua. Eu fiquei com muito medo, porque diziam muitas coisas de moradores de rua, que eles eram inconvenientes, que eles matavam, que se drogavam... Mesmo assim, eu disse eu vou aceitar esse desafio. Eu vim pra cá e, logo que cheguei aqui e conheci eles, gostei muito de trabalhar com eles. São pessoas amáveis (Alfabetizadora 1-UEA).

Ao ser indagada acerca do que faziam para resgatá-los/as das ruas e mantê-los/as no espaço educativo ela respondeu: O segredo é carinho, quando estiver com eles, tratá-los bem. Isso aí eles gostam muito. Se você for lutar contra eles, se estressam e vão embora, pegam as coisas e vão embora. Tem uns que, quando tão muito estressados rasgam até a camisa... (Alfabetizadora 1-UEA).

A alfabetizadora 1-UEA, ao relatar os fatos, gesticulava e dramatizava as ações com as mesmas expressões de estresse dos sujeitos quando se viam, segundo ela, acuados ou com sua liberdade ameaçada. Aí eles vão se acalmando, com carinho, trabalhar com carinho é o segredo, finaliza. (Alfabetizadora 1-UEA). O olhar petrificado no consciente da alfabetizadora, quando expressou seu medo no início do trabalho, pode ser compreendido por meio da teoria da pseudo-concreticidade como o mundo dos fenômenos externos que se desenvolvem na superfície dos processos realmente essenciais (KOSIK, 1976). Mediante essa compreensão, Freire (1987) nos convida a refletir sobre a capacidade cognoscitiva dos seres humanos que ocorre na medida em que começam não só a saber que vivem, mas a saber que sabem e que, desta forma, podem saber mais. No caso estudado, a prática docente brota no processo gerando saberes da própria ação.

A alfabetizadora 2-UFAM expressou-se de forma semelhante à sua parceira de trabalho, ao relatar que:

Como eles são pessoas de rua e, quando a gente percebe que eles estão se afastando, estão ficando ausentes, a gente começa a fazer o trabalho de resgatá-los. A gente já cansou de ir lá pelo mercado, pelas praças, até pela praça da matriz tentando encontrá-los e convidando sempre pra que eles venham. E, no outro sábado, geralmente, eles estão aqui conosco. Nós quisemos levar isso assim, acreditando que é possível, e é! Vocês estão vendo o resultado. Eles são pessoas muito boas que precisam de amor. Primeiramente de carinho, compreensão e, na medida do possível, a gente tenta passar isso pra eles (Alfabetizadora 2-UFAM, 2009). 
Cleu continuou na rua, mas freqüentou as aulas todos os sábados. Ele reconhece e valoriza o trabalho feito pelo projeto, compreendendo a importância das ações desenvolvidas em parceria com outras instituições de onde lhes eram disponibilizados alimentação, transporte e espaço físico para as aulas. Seu texto ao final do projeto revelou carinho e gratidão às duas educadoras pela paciência e dedicação durante o convívio com o grupo, e, principalmente, por ensiná-lo a amar.

Van demonstrou mais sensibilidade e disse agora estar mais consciente e desejosa de voltar para a família, afirmando que: [...] tem coisas que sei e coisas que não sei. Aprendi a cuidar mais de mim e das coisas que compro ou ganho. [...] parei na primeira série. Fiquei no projeto, porque quero ter um emprego e quero ter uma casinha.

\section{5| CONSIDERAÇÕES FINAIS}

Ao término da pesquisa, algumas marcas foram evidenciadas: baixa evasão, diminuição em $50 \%$ dos indicadores negativos, letramento com as temáticas trazidas pelos/as educandos/as, possibilidade de leitura do mundo a partir da realidade do grupo, inserção ao ensino formal, retorno aos lares com a autoestima elevada e a vontade de ser gente se reconhecendo enquanto ser inacabado mesmo na condição de se sentirem de e na rua.

Um trecho da carta no final do projeto escrita por Cleu à sua mãe revela esse sentimento: "Manaus, 13 de feverero de 2010. Querida mamãe, escrevo-lhe esta carta para lhe falar que estou muito feliz com as ótimas pessoas que encontrei [...]". Essa investigação, assim como as pesquisadoras, são consideradas inacabadas.

Portanto, encerramos este momento, com o compromisso de desvelar os questionamentos postos resgatando quatro temas considerados neste estudo, conceitos-chave do pensamento do educador Paulo Freire e que resumem as preocupações abordadas neste texto para reflexão: em que medida a construção do conhecimento é uma possibilidade para a educação? Em que sentido o conhecimento crítico do mundo é um ato de mudança material do mesmo? Será por meio da comunicação dialógica que nos damos conta da materialidade física e temporal do conhecimento e da transformação do mundo?

E por fim, porém não menos importante, como a pedagogia crítica se vincula com a destruição da pseudoconcreticidade e, portanto, com a libertação do homem? 


\section{Referências}

BENCHIMOL, Samuel. Amazônia: Um pouco - Antes e Além - Depois. llustração de Jorge Palheta e Moacir Andrade; Prefácio de Artur Cezar Ferreira Reis. Manaus: Umberto Calderaro, 1977.

CALDART, Roseli Salete et al (Org). Dicionário da Educação do Campo. 2 ed. Rio de Janeiro e São Paulo: Escola Politécnica de Saúde Joaquim Venâncio e Expressão Popular, 2012.

FELDMANN, Marina Graziela. Formação de Professores e Escola na Contemporaneidade. São Paulo: Senac, 2009.

FREIRE, Paulo. Papel da Educação na Humanização. In. Revista da FAEEBA, Salvador, nº 7, jan/junho, 1997.

Pedagogia da autonomia: saberes necessários à pratica educativa. São Paulo: Paz e Terra, 1996.

Cortez, 1991.

A Educação na Cidade. São Paulo:

Pedagogia do Oprimido. 17 ed. Rio de Janeiro: Paz e Terra, 1987.

FREITAS, Marcílio \& SILVA, Marilene Corrêa. Estudos da Amazônia Contemporânea: Dimensões da Globalização. Manaus: Universidade do Amazonas, 2000. 308 p. ISBN 85-7401-057-X.

GADOTTI, Moacir. SIGNIFICADO E DESAFIO DA EDUCAÇÃO BÁSICA INTERNATIONAL WORKSHOP - WORLD UNIVERSITY SERVICE (WUS) "Education for All: A Challenge for Democracy and Human Rights" NEW DELHI - INDIA - 6-8 September. Instituto Paulo Freire Universidade de São Paulo, Brasil, 1991.

GARCEZ, A.; DUARTE, R.; EISENBERG, Z. Produção e análise de vídeo gravações em pesquisas qualitativas. Educação e Pesquisa. São Paulo, v. 37, n.2, p. 249-262, mai./ago, 2011.
KOSIK, Karel. Dialética do Concreto. 2 ed. Rio de Janeiro: Paz e Terra, 1976.

MENGA, Lüdke \& ANDRÉ, Marli. Pesquisa em Educação: Abordagens Qualitativas. São Paulo: EPU, 1986.

MONTEIRO, Mário Ypiranga. História da Cultura Amazonense. Manaus: Universidade do Amazonas, 1998.

LIMA, Fernando Henrique de. UM MÉTODO DE TRANSCRIÇÕES E ANÁLISE DE VIIDEOS: A EVOLUÇÃO DE UMA ESTRATÉGIA. Disponível em: <http://www. ufjf.br/emem/files/2015/10/UM-M\%C3\%89TODO-DETRANSCRI\%C3\%87\%C3\%95ES-E-AN\%C3\%81LISEDE-V\%C3\%8DDEOS-A-EVOLU\%C3\%87\%C3\%83ODE-UMA-ESTRAT\%C3\%89GIA.pdf.> Acesso em 23 out. 2016.

ROSA, João Jesus. Intertexto e Identidade Cultural em Aquele UM, de Benedicto Monteiro. Dissertação/UFPE, 2003. Disponível em: <http://www.repositorio.ufpe.br/ bitstream/handle/123456789/7929/arquivo8146_1.pdf? sequence=1\&isAllowed=y> Acesso em 03 mai. 2016.

TORRES SANTOMÉ, Jurjo. Currículo Social e Justiça Social: o cavalo de Tróia da educação. Porto Alegre: Penso, 2013.

UNIVERSIDADE DO ESTADO DO AMAZONAS. PROFORMAR. Antropologia e Educação. ed. rev. Manaus: Universidade do Estado do Amazonas, 2005.

UNIVERSIDADE DO ESTADO DO AMAZONAS. PROFORMAR. Relatório da ações do Programa de Letramento Reescrevendo o Futuro. Manaus: UEA, 2010.

UNIVERSIDADE DO ESTADO DO AMAZONAS. PROFORMAR. Resgate Social. Vídeo Gravação, Derzi Produções. Manaus: UEA, 2009. 